\title{
Drill Monitoring for Rock Mass Grouting: Case Study at the Stockholm Bypass
}

\author{
Jeroen van Eldert ${ }^{1}\left[\right.$ ] Johan Funehag ${ }^{1}\left[\right.$ (]) Håkan Schunnesson ${ }^{1} \cdot$ David Saiang $^{1} \mathbb{C}$
}

Received: 18 February 2020 / Accepted: 12 October 2020 / Published online: 27 October 2020

(c) The Author(s) 2020

\begin{abstract}
In tunneling, rock mass grouting is a method applied to reduce water ingress. Grouting is influenced by rock mass conditions, especially apertures, frequency, and continuation of fracturing. These rock mass conditions can partly be determined by rock mass classification systems. At the Stockholm bypass, the Measurement While Drilling (MWD) Fracturing Index was applied to characterize the rock mass for grouting purposes, with a focus on adjusting the grout hole drill plan to minimize environmental impact. This study divided the rock mass in a $1.9 \mathrm{~km}$ tunnel into six categories based on rock mass conditions, identifying rock mass quality, apparent fracturing, and grout consumption. These categories were then compared with the mean fracturing index based on the coefficients of penetration rate and rotation pressure variations, as well as grout consumption at each grout umbrella. The fracturing index was $93 \%$ successful in assessing favorable and unfavorable rock mass conditions in the studied tunnel and $85 \%$ successful in determining grout consumption. Finally, a conceptual method was developed to reduce the grouting activities using the MWD fracturing index and water loss tests. The introduction of this conceptual method for grouting decisions could potentially reduce $59 \%$ of the umbrellas found in the case study.
\end{abstract}

Keywords Tunneling $\cdot$ Measurement While Drilling (MWD) $\cdot$ Rock mass grouting $\cdot$ Rock mass quality $\cdot$ Rock mass classification

\section{Introduction}

Rock mass grouting is an integral part of tunnel excavation in Scandinavia. The grout hole drilling and grouting is a time consuming and costly process. The grouting procedure has a considerable impact on the environment, both energy consumption (for drilling and production of cement) and the introduction of foreign material in the rock mass (cement). The Swedish traffic administration (Trafikverket) strives to minimize the environmental impact of infrastructure projects, both during construction and operation.

The purpose of this paper is to investigate the capability of Measurement While Drilling (MWD) technology to aid in Trafikverket's commitments on reducing drilling and cement use while following the environmental regulations on water

Jeroen van Eldert

jeroen.van.eldert@1tu.se

1 Division of Mining and Geotechnical Engineering, Department of Civil, Environment and Natural Resources Engineering, Luleå University of Technology, Luleå, Sweden ingress into the tunnels. Therefore, the grout consumption was compared with the MWD Fracturing Index (FI) of the rock mass while considering the observed rock mass conditions. This study concentrates on determining the rock mass conditions for grouting purposes by MWD recordings. It does not investigate the optimal grout umbrella design, neither the optimum grout mixtures, e.g., water-cement ratio, retarder and accelerator additions, grouting procedures, e.g., grouting pressure, flow, and stop-criteria, nor determination of rock mass hydraulic domains. Although all these have a major impact on the success of rock mass grouting, they are outside of the scope of this study.

\subsection{Measurement While Drilling}

MWD technology is used to collect drilling parameters, and these normally include penetration rate, feed pressure, percussive pressure, rotation pressure, and water flow (International Organization for Standardization [ISO] 2016). Based on the MWD parameters a fracturing index (FI) can be extracted. Broadly stated, the MWD fracturing index describes the rock mass heterogeneity. Schunnesson (1996, 
1998), Martinsson and Bengtsson (2010), Rødseth (2013), Høien and Nilsen (2014), Ghosh et al. (2017) and Van Eldert et al. (2020a, b) aimed to correlate rock mass quality (RQD and/or $Q$ value) and mapped fracture areas to a fracturing index. MWD parameters were successfully correlated with rock mass fractures using diamond drill core logging (Schunnesson 1996, 1998), geological mapping (Rødseth 2013), or drill hole filming (Ghosh et al. 2017; Navarro et al. 2018). Others took a holistic, visual approach (Van Eldert et al. 2020a, b) comparing the MWD rock mass characterization with the geotechnical mapping of tunnels.

The FI portrays the rock mass conditions most accurately when based on penetration rate (PR) and rotation pressure (RP) variations according to Schunnesson (1996), Ghosh et al. (2017) and Van Eldert et al. (2020b). In these publications, the MWD data was filtered and normalized for the influence of feed pressure and percussive pressure variations. Schunnesson (1996) employed MWD data logging in the Glödberget tunnel to assess the rock mass quality. This study showed a good correlation between the RQD and the penetration rate and torque pressure (or rotation pressure). These findings indicated that increased RQD leads to a decreased penetration rate and decreased torque pressure. Rødseth (2013) showed a moderate to good correlation between MWD parameters and RQD in the Eikrem, Løren, and Oppdølstranda tunnels in Norway, but, a poor correlation was found between MWD and degree of jointing $\left(\mathrm{RQD} / J_{\mathrm{n}}\right)$. As a result, the numerical comparison between MWD parameters and rock mass quality was deemed unreliable. Ghosh et al. (2017) implemented the fracturing index based on penetration rate and rotation pressure for chargeability of blast holes at LKAB's Malmberg mine in Northern Sweden. Here, borehole TV showed a good correlation with variations in the fracturing index based on the variation of the penetration rate and rotation pressure. Based on the found correlations a model was defined, where rock mass conditions such as fractured rock masses and cavities could be identified. Van Eldert et al. (2020a) applied a normalized penetration rate and normalized to identify fracture zones in an $80 \mathrm{~m}$ tunnel roof at the Stockholm bypass. This study showed numerical correlations between MWD parameters, rock mass quality and rock support are not reliable and show large dispersion. Van Eldert et al. (2020a) introduced a holistic approach to relate MWD parameters with rock mass quality and support as an extension of the results from Epiroc's Underground Manager MWD (Van Eldert et al. 2020b). This approach combined normalized penetration rate and normalized rotation pressure to identify fracture areas in the tunnel roof (Van Eldert et al. 2020a). The study demonstrated that this combination of MWD parameters was able to distinguish fractured areas in the tunnel roof. This was broadened to predict the rock support requirements in the tunnel roof based on the normalized MWD parameters.
On the other hand, Navarro et al. (2018) combined percussive pressure (PP), feed pressure (FP) and rotation pressure (RP) of unprocessed MWD data to derive the coefficient of variations (CVs) for the fracturing index. Navarro et al. (2018) correlate this combination of MWD parameters to fractures identified with borehole TV.

\subsection{Rock Mass Grouting}

Pre-grouting is performed to reduce the hydraulic conductivity of a rock mass and ultimately water ingress (Gustafson and Stille 1996). The flow of grout in the rock mass was described by Doe and Geier (1990). They established three conductive grout flow path geometries within rock masses. These paths were channel (linear, 1D) flow within one fracture, radial (2D) flow in a fracture plane or spherical (3D) flow within a fracture network. These paths affect the flow behavior during grouting as well as the required volume of grout to reduce the rock mass transmissivity for water ingress. Kvartsberg (2013) developed a rock mass classification based on hydraulic conductivity domains for the host rock and conductors. The hydraulic domains were separated into hydraulic rock domains (host rock, including minor alterations) and hydraulic conductor domains (fracture zones). The hydraulic conductor domains include local, distributed or combined conduits-barriers for water flow within the fracture zone. The conductors were noted as the main contribution to water ingress of tunnels, thus the focus of a grouting operation. Concurrently to Kvartsberg (2013) and Hernqvist et al. (2012) created a conceptual model for the adaptation of the grout design of the water-conductive fracture systems, focusing on grouting these fracture systems.

Widmann (1996) published an extensive review of international grouting practices, and the article was the result of the combined efforts by the International Society for Rock Mechanics (ISRM) commission on rock grouting. The article addressed the main considerations with grouting. Widmann (1996) states that grouting success is accomplished by trial and error based on the experience of the grouting contractor. The grouting procedure should define the grouting material, pressure, borehole spacing and required grouting value to reach the desired goal economically. The procedure should consider grouting purpose, rock mass properties and conditions, grouting material, and equipment. In hard rock tunneling, the main purpose of the grouting is to reduce the rock mass transmissivity. For this purpose, the groutability is related to the hydraulic properties of the rock mass. These hydraulic properties are dictated by the flow paths (1D, $2 \mathrm{D}$, and $3 \mathrm{D}$ ), water flow and pressure in the rock mass, degree of sedimentation in the flow paths, expansion of the flow paths (erosion and jacking), temperature of the rock mass, stress regime, and cavities. To obtain these 
properties geo-statistics can be applied to model the rock mass to determine joint orientation, spacing (frequency), dimensions, roughness, opening widths, and fracture intensity. Besides, geophysical methods (seismicity) could be used to determine large discontinuities. The hydraulic properties should be determent by water tests to establish the rock mass transmissivity and flow regime. Analysis of these test results should consider the structure of flow paths and the rheological differences between water and grout (Widmann 1996).

Before tunnel excavation, a grouting program is developed. For Swedish rock mass conditions, this grouting program includes grouting objective, rock mass classification, grouting guidelines, stop criteria and limitations of the grouting process (Gustafson and Stille 1996). The main aim of the grouting program is to reduce the rock mass transmissivity to adhere to the water ingress limits set for the tunneling project. The stop criteria are calculated based on grout properties (yield strength and viscosity), rock mass characteristics (fracture aperture, number of fractures, persistence of fractures, communication between fractures, and groundwater pressure), and operational practices (set grouting pressure and theoretical grouting time) (Gustafson and Stille 2005). In addition, a common Swedish grouting program takes into consideration rock cover and rock strength to avoid jacking and damaging the rock mass. The success of a grouting program is defined by the reduction of hydraulic transmissivity and water ingress, as well as grout penetration into fractures, reduction of excessive pumping and the limited grout backflow (Gustafson and Stille 1996).

\subsection{Grouting and Rock Mass Quality}

The rock mass quality is in Scandinavian infrastructure tunneling is commonly characterized by the $Q$-system (Barton et al. 1974). The effect of rock mass quality on grouting was investigated by Bhasin (2002). Who studied the relation between the $Q$-system parameters and the grout volume at the Frøya tunnel in Norway. This study showed a trend between the $Q$-parameters and the grout intake; low-quality rock masses (low $Q$-value) are fractured and have increased grout consumption. It indicated a correlation between rock mass quality and grout consumption, although a thorough review of this paper shows only a weak correlation. Palmström and Broch (2006) described the $Q$-system unsuitable for grouting, because it lacks parameters on joint aperture and channel forming, which contribute majorly to the grout flow and total grout volume. Besides, they addressed a high $J_{\mathrm{r}} / J_{\mathrm{a}}$-ratio in large open, irregular joints (high $Q$-value) increase grout consumption, contradicting the apparent, negative correlation between $Q$ and grout consumption. In addition, clay-filled fractures may seal the rock mass, limit grout spread and resulting in lower grout consumption.

\subsection{Measurement While Drilling and Rock Mass Grouting}

Martinsson and Bengtsson (2010) employed an MWD fracturing index with limited success on a hole-by-hole basis to optimize pre-grouting, allocating additional grout holes in highly fractured index areas at Stockholm's Norra Länken project in Sweden. In this case, the fracturing and rock strength indices were used to establish rock mass conditions. The degree of fracturing was characterized by the percentages of the drill hole samples within a certain fracturing and water indices intervals in Rockma's GPM software. Based on the assessment of these indices, additional grout holes were drill in the indicated fractured rock masses. Høien and Nilsen (2014) applied the same software package to successfully obtain a medium correlation between MWD indices, water ingress, and grout volume per grout umbrella at the Løren tunnel in Norway. This study used the obtained percentage of a drill hole above a set fracturing index value to describe the degree of fracturing. Unfortunately, these studies (Martinsson and Bengtsson 2010; Høien and Nilsen 2014), on grouting performance in relation to MWD, build on results from Rockma's GPM. The manual for this software package does not address how the indices are calculated.

The contribution of this paper is the development of a conceptual method to reduce the number of grout umbrellas, based on the establishment of rock mass categories while pursuing openness on the concept and calculated MWD values. Previous studies have shown a correlation between rock mass conditions, MWD indices, and grout consumption. But, except for Norra Länken (Martinsson and Bengtsson 2010) and by extension Stockholm bypass (Zetterlund et al. 2017), no attempts have been made to incorporate MWD technology in grout requirement assessments. Though in these two cases the establishment of rock mass fracturing, hardness and water indices was unknown.

\section{Case Study}

The Stockholm bypass project aims to improve north-south road transport links surrounding Stockholm, Sweden. The project includes $18 \mathrm{~km}$ of double-tube main road tunnels and $20.6 \mathrm{~km}$ of auxiliary tunnels (Trafikverket 2018). This study concentrated on Tunnel 201 at the southern end of the bypass. Rock extracted at the tunnel excavation is mainly gray, medium to large grained granite-gneiss (Arghe 2016). The rock mass has minor areas with foliated granite, pegmatite intrusions, greenstone veins, areas with 


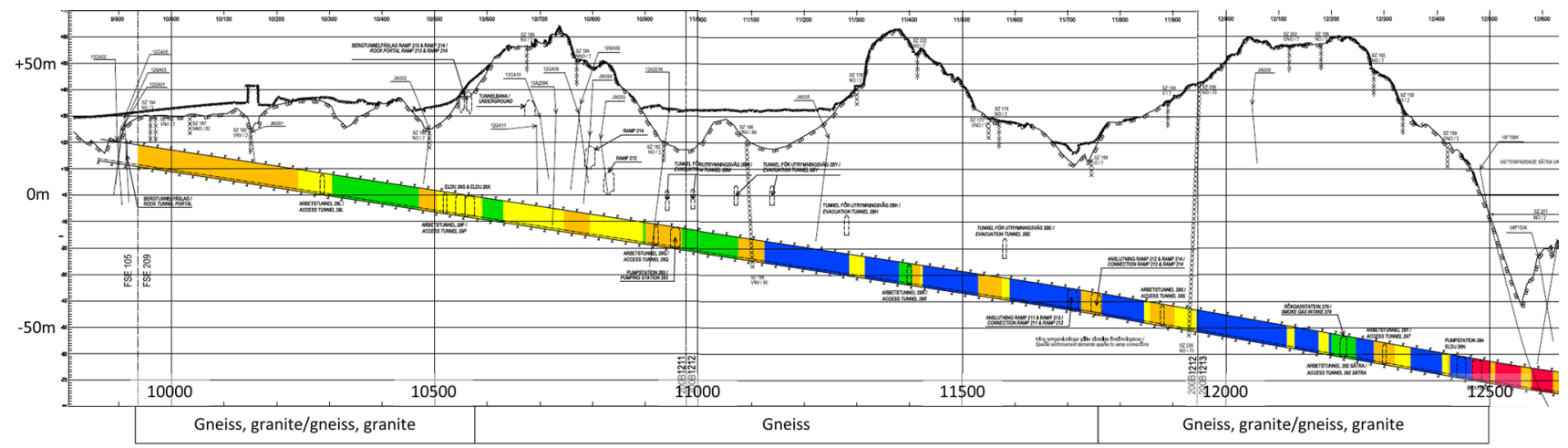

\begin{tabular}{|c|c|c|c|l|}
\hline $\begin{array}{c}\text { Rock } \\
\text { class }\end{array}$ & Q-value & Rock quality & Description of rock mass \\
\hline I & $Q>10$ & Very good & $\begin{array}{l}\text { Sparsely fractured or large blocky granite, gneiss-granite, pegmatite or occasionally slaty gneiss. Mainly rough fracture } \\
\text { surfaces with no or little fracture filling. Average block edge length }>2 \mathrm{~m} \text {. Three or fewer fracture sets. }\end{array}$ \\
\hline II & $4<Q \leq 10$ & Good & $\begin{array}{l}\text { Large or medium blocky granite, gneiss-granite, pegmatite or moderate slaty gneiss. Mainly rough fracture surface with little } \\
\text { fracture filling. Average block edge length 0.6-2m. Three or more fracture sets. }\end{array}$ \\
\hline III & $1<Q \leq 4$ & Fair & $\begin{array}{l}\text { Medium to small blocky granite, gneiss-granite, pegmatite or slaty gneiss. Fracture surfaces are rough to smooth, with } \\
\text { moderate fracture filling. Average block edge length 0.2-0.6m }\end{array}$ \\
\hline IV & $0.1<Q \leq 1$ & Poor & $\begin{array}{l}\text { Small blocky to crushed, metamorphic granitic rock mass or heavily slated gneiss with mineral-filled fractures. Average edge } \\
\text { length <0.2m. }\end{array}$ \\
\hline V & $Q \leq 0.1$ & Very poor & $\begin{array}{l}\text { Tectonically heavily affected, disjointed rock mass, fracture and crush zones. Mainly smooth, polished fracture surfaces filled } \\
\text { with large amounts of soft minerals. }\end{array}$ \\
\hline
\end{tabular}

Fig. 1 Tunnel 201 profile with expected fracture zones and rock classes from the pre-investigation (modified after Trafikverket 2015a, b, c) and the rock classes and descriptions at the Stockholm bypass (after Arghe 2016)

graphite, clay, and several fracture zones (Arghe 2016). The tunnel profile of the investigated sections is displayed in Fig. 1. The figure displays the rock classes with their $Q$-value range established during the site investigation.

During the tunnel excavation the tunnel was geotechnically mapped (Å 2016-2019). The granite-gneissic host rock had a uniaxial compressive strength of 100-250 MPa in an undisturbed rock mass, dropping to $50 \mathrm{MPa}$ in a disturbed rock masses and to $<5 \mathrm{MPa}$ in fracture zones. The weathering was mainly between weathering class W0 (no weathering, 0\%) and W3 (sever weathering, 51-75\%), with sections of W4 (complete weathering, structure remaining, 76-99\%) and at section 12,500 weathering class W5 (complete weathering, structure disappeared, $100 \%$ ).

Based on previous experience in Stockholm's Norra Linken (Martinsson and Bengtsson 2010), a comprehensive grouting plan was established before excavation (Zetterlund et al. 2017). The plan incorporated MWD indices to adjust the number of grout holes during grout umbrella drilling, as displayed in Fig. 2. The grouting holes for this part of the Stockholm bypass project were drilled by five different Epiroc WE3 three boom drill rigs, which logged the MWD data. The grouting was performed by grouting equipment produced by AMV and Bever Control. During the excavation, a $30 \mu \mathrm{m}$ cement-based mixture was used for the pre-grouting. The most common water-cement ratio (W/C ratio) used for Tunnel 201 was $0.95(60 \%)$. Although mixtures ranging from $W / C$ ratio $0.75(16 \%)$ to $W / C$ ratio 1.5 (8\%) were used during the tunnel construction. The grouting pressure ranged between 20 and 50 bar,

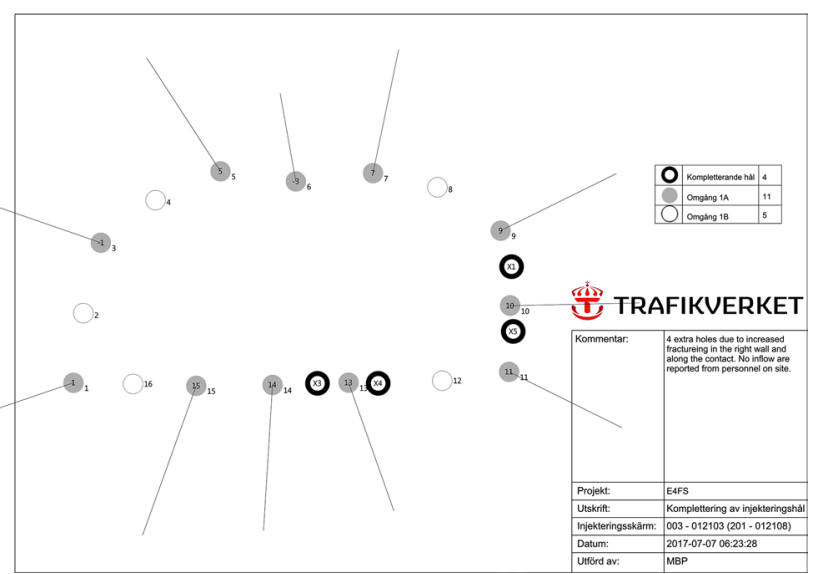

Fig. 2 Grout umbrella of section 12,108 in Tunnel 201 (Trafikverket 2017). The gray circles indicate the first round of planned grout holes, the white circles the second, and the black circles the additional grout holes required based on analysis of the MWD data. The nominal main tunnel width is between 12 and $17 \mathrm{~m}$

depending on the expected rock mass conditions and rock cover.

\section{Methodology}

The tunnel was continuously geotechnically mapped after each excavation round ( $5 \mathrm{~m}$ ) ( $\mathrm{AF} 2016-2019)$. The mapping data included the $Q$-value assessment and the rock mass description. The rock mass was divided into rock 
mass classes based on the $Q$-system; see Fig. 1. In addition, the grouting volume and hole length were measured for each grout hole, the MWD sampling was performed every $2-3 \mathrm{~cm}$ in each drill hole. The $Q$-value includes the water reduction factor $\left(J_{\mathrm{w}}\right)$ and the stress reduction factor (SRF), unfortunately, these cannot be measured with the drill system and do not affect the used MWD parameters. During the excavation of the Stockholm bypass, the SRF locally increased because of rock cover, variation in tunnel span, and construction of tunnel intersections, to increase the study's reliability the $Q_{\text {base-value was used. }}$ The $Q_{\text {base }}$-value only considers the rock mass conditions, e.g., degree of fracturing $\left(\mathrm{RQD} / J_{\mathrm{n}}\right)$ and fracture conditions $\left(J_{\mathrm{r}} / J_{\mathrm{a}}\right)$. For this paper, the rock classes in Fig. 1 were used as a guideline.

Rock mass class III or higher was designated as unfavorable $\left(Q_{\text {base }} \leq 4\right)$ for this study. For the grout consumption, the $98 \%(\mu+2 \sigma, 5.5 \mathrm{~L} / \mathrm{m})$ limit of the first normal distribution mode for grout take per hole was used to distinguish between low/normal and high grout take. The mapping, grout hole and MWD data were compared at a grout umbrella level, because of possible communication between grout holes and uncertainty in relating MWD hole data to grout consumption for each grout hole. Based on fracture occurrence, aperture type and filling, the rock mass was divided into six categories, as displayed in Fig. 3. For each category, the expected fracturing index was established. The fracturing index (FI) is a measure of the rock mass heterogeneity. This heterogeneity displays the variation of rock mass-dependent parameters; the penetration rate and rotation pressure (Brown and Barr 1978). The variation can occur with the interaction of a section with a large degree of fracturing, fracture zone, or rock masses with $\geq 2 \mathrm{~cm}$ phenocrysts (Van Eldert et al. 2016). In these cases, the drill parameters vary significantly and a high fracture index is recorded. Homogeneous rock mass, with no or few fractures, are expected to display a low variation of the drilling parameters, resulting in a low fracturing index. In this study, the use of the mean FI for each grout-hole was used. The mean FI is less robust than the median FI. The mean FI was specifically selected due to the skewness of the FI. The use of the mean FI gives more weight to high-value FI. This is preferable in this study, since more fractured areas are expected to display a disproportional larger grout consumption. In addition, the expected grout consumption was taken into consideration with the establishment of the rock mass grouting categories in Fig. 3. Rock masses with few large open fractures (category D) may have a high grout consumption, albeit being homogeneous (low FI). Rock masses with clay-filled fractures (category E) and intrusive dikes (category F) may have a low grout consumption, albeit being heterogeneous (high FI). In practice, rock mass transitions between categories exist, based on the

\begin{tabular}{|c|c|c|c|c|c|}
\hline Category A & Category B & Category $\mathrm{C}$ & Category D & Category E & Category F \\
\hline $\begin{array}{l}\mathrm{No} / \mathrm{few} \\
\text { fractures }\end{array}$ & $\begin{array}{l}\text { Many } \\
\text { fractures }\end{array}$ & $\begin{array}{l}\text { Large } \\
\text { fracture } \\
\text { zone }\end{array}$ & $\begin{array}{l}\text { Few large } \\
\text { fractures }\end{array}$ & $\begin{array}{l}\text { Clay-filled } \\
\text { fractures }\end{array}$ & $\begin{array}{l}\text { Intrusive } \\
\text { dikes }\end{array}$ \\
\hline & 11 & & & & \\
\hline $\begin{array}{l}\text { Expected: } \\
\text { Low } \\
\text { fracturing } \\
\text { index }\end{array}$ & $\begin{array}{l}\text { Expected: } \\
\text { High } \\
\text { fracturing } \\
\text { index }\end{array}$ & $\begin{array}{l}\text { Expected: } \\
\text { High } \\
\text { fracturing } \\
\text { index }\end{array}$ & $\begin{array}{l}\text { Expected: } \\
\text { Low } \\
\text { fracturing } \\
\text { index }\end{array}$ & $\begin{array}{l}\text { Expected: } \\
\text { High } \\
\text { fracturing } \\
\text { index }\end{array}$ & $\begin{array}{l}\text { Expected: } \\
\text { High } \\
\text { fracturing } \\
\text { index }\end{array}$ \\
\hline
\end{tabular}

Fig. 3 Rock mass categories with the expected effects on grout consumption and fracturing index

parameter values and observation a section may belong to multiple categories. In these cases, the sections were assigned to the best fitting category.

The categories bear a resemblance to the hydraulic domains established by Kvartsberg (2013). However, in this case study, the categories were selected purely to investigate the potential of the MWD fracturing index to verify and predict rock quality and grouting requirements, not to establish precise hydraulic domains. Admittedly, though, the MWD categories can be used in adjunction with the hydraulic domains as a complementary data set to determine rock mass conditions for grouting purposes.

The data were collected from 97 grout umbrellas over $1.9 \mathrm{~km}$. The collected MWD data were normalized following Van Eldert et al.'s (2020c) proposed procedure. This normalization and filtering process includes the filtration of the drill hole collar and coupling data points and the rod-dependent normalization of the drill hole length and feed pressure for each drill rig and rock drill individually. Based on the combined experience of studies using MWD-based predictions of rock mass quality, the fracturing index was established by integrating the $\mathrm{CVs}$ of the penetration rate and rotation pressure, which are established as the main responds parameters for rock mass fracturing (Schunnesson, 1998; Haukaas 2010; Ghosh et al. 2017; Van Eldert et al. 2020a). The calculation of the fracturing index used in this study is displayed in Eqs. (1) and (2). Besides, grout consumption data were collected at 2646 grout holes and normalized in consumption per meter $(\mathrm{L} / \mathrm{m})$. The theoretical volume for filling a grout hole is $3.21 \mathrm{~L} / \mathrm{m}$, based on the $\phi 64 \mathrm{~mm}$ drill bits used for drilling. A total of 2536 grout holes were reliably related to the MWD data. The average grout consumption, fracturing index and $Q_{\text {base-value were calculated for each grout }}$ umbrella. These values were compared for each umbrella; based on its appearance, each grout umbrella was assigned to the best fitting category. Finally, the categories were used to develop a conceptual method for the application of the fracturing index and external information to determine pregrouting requirements: 
$\mathrm{MWD}_{\mathrm{var}}=\sum_{i}^{N+i}\left|\frac{\sum_{i}^{N+i} \mathrm{MWD}_{i}}{N+1}-\mathrm{MWD}_{i}\right| \quad$ (after Ghosh et al. 2017),

Fracturing Index $=\sqrt{\frac{\mathrm{PR}_{\mathrm{var}}}{\overline{\mathrm{PR}}}}+\sqrt{\frac{\mathrm{RP}_{\mathrm{var}}}{\overline{\mathrm{RP}}}}$

where $N$ : number of the considered additional sample (here, $N=4), \mathrm{MWD}_{i}$ : MWD sample value, $\mathrm{MWD}_{\text {var }}$ : MWD variation over 1:N, $\overline{\mathrm{MWD}}$ : hole average MWD value, here penetration rate $(\mathrm{PR})$ and rotation pressure (RP).

\section{Results and Discussion}

In this study, the MWD data was collected in 2536 grout holes. The data included more than 1.8 million MWD samples and the FI was calculated for each sample. The FI distribution is characterized by a lognormal distribution with a $\mu_{\log }$ of 0.089 and a $\sigma_{\log }$ of 0.291 , see Fig. 4 . The overall fracturing index mean was 1.14. Based on these FI values the mean FI for each grout hole and umbrella was calculated. The overall mean was used as a guideline to separate high fracturing index and low fracturing index umbrellas for rock mass grouting categorization.

Figure 5 displays the number of grout holes (frequency) at the different grout consumption intervals. In this case study, the average grout consumption was $3.57 \mathrm{~L} / \mathrm{m}$ per grout hole for the first mode of the grout consumption distribution, with a standard deviation of 0.94 .

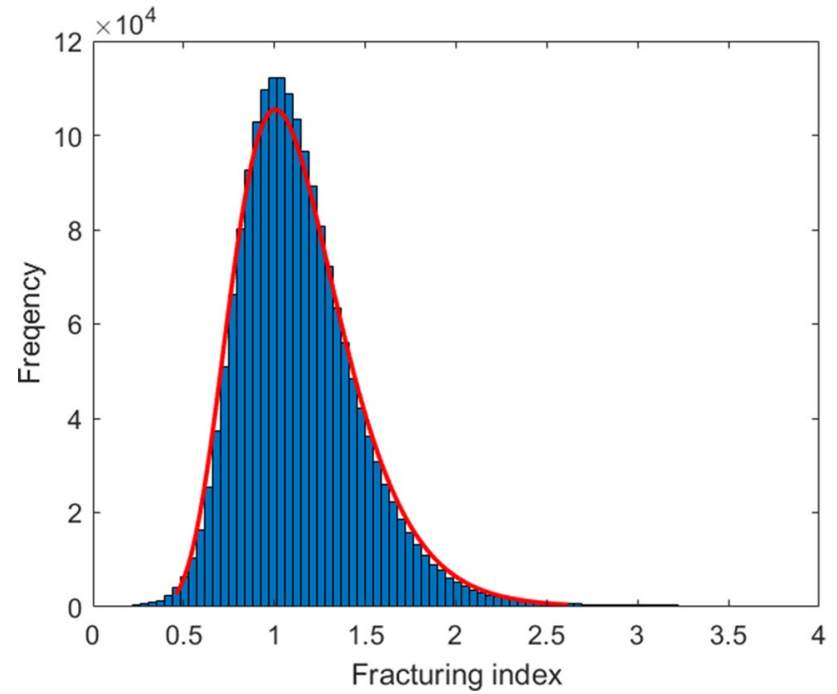

Fig. 4 Fracturing index for the 1.8 million samples. Curve fitting showed the fracturing index has a lognormal distribution with $\mu_{\log }=0.089$ and $\sigma_{\log }=0.291$. The fracturing index had a mean of 1.14 and a median of 1.09
Of the 97 umbrellas investigated, 27 consumed on average high quantities of grout $(\geq 5.5 \mathrm{~L} / \mathrm{m}$ hole, $\mu+2 \sigma)$. The grout consumption, $Q_{\text {base-value and mean fracturing index }}$ for the grout umbrellas in Tunnel 201 are shown in Fig. 6. Of the investigated umbrellas, twelve were rock class I ( $\left.Q_{\text {base }}>10\right), 25$ rock class II $\left(4<Q_{\text {base }} \leq 10\right), 45$ rock class III $\left(1<Q_{\text {base }} \leq 4\right)$ and 15 rock class IV $\left(Q_{\text {base }} \leq 1\right)$. An increased mean fracturing index $(\mathrm{FI}>1.14)$ was determined for 40 grout umbrellas.

In general, Fig. 6 shows poor quality rock masses $\left(Q_{\text {base }} \leq 4\right)$ in an umbrella have in most cases a high fracturing index $(F I \geq 1.14)$ and high grout consumption $(\geq 5.5 \mathrm{~L} / \mathrm{m})$. The umbrellas with good quality rock masses $\left(Q_{\text {base }}>4\right)$ showed a relatively low fracturing index $(\mathrm{FI}<1.14, \mu)$ and low grout consumption $(<5.5 \mathrm{~L} / \mathrm{m})$. In addition, the grout consumption does not reduce significantly when the rock mass quality exceeds $Q_{\text {base }}>4$. Besides, the FI shows significant variations. This is most likely caused by the calculation method. Using the average FI of each umbrella, locally "fractured" areas could affect the values significantly. In general, this confirms the expectations made with the categories established in Fig. 3. Figure 7 displays the FI and grout consumption side by side. The linear correlation over all the umbrellas between these two values is moderate $(R=0.36)$, but if the outliers are removed (red squares in Fig. 7) the correlation is relatively strong $(R=0.58)$. These outliers are mostly related to categories $\mathrm{C}, \mathrm{E}$ and $\mathrm{F}$, as well as a significant increase in grout consumption $(15.8 \mathrm{~L} / \mathrm{m})$ in one category B umbrella.

Several umbrellas displayed in Fig. 6 had discrepancies. These are explained by occurrences of local fracture zones (high grout consumption, medium $Q_{\text {base }}$ and medium FI at 14 umbrellas), high clay content (low grout consumption,

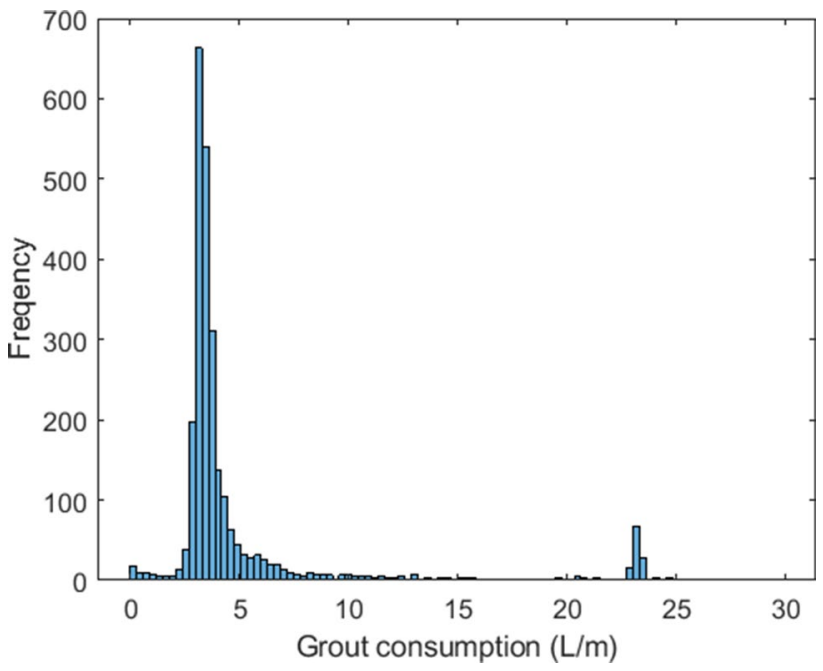

Fig. 5 Grout consumption distribution in the individual grout holes in Tunnel 201 
Fig. 6 Grout consumption, $Q_{\text {base-value and mean fracturing }}$ index in Tunnel 201 (a) Tunnel 201 South

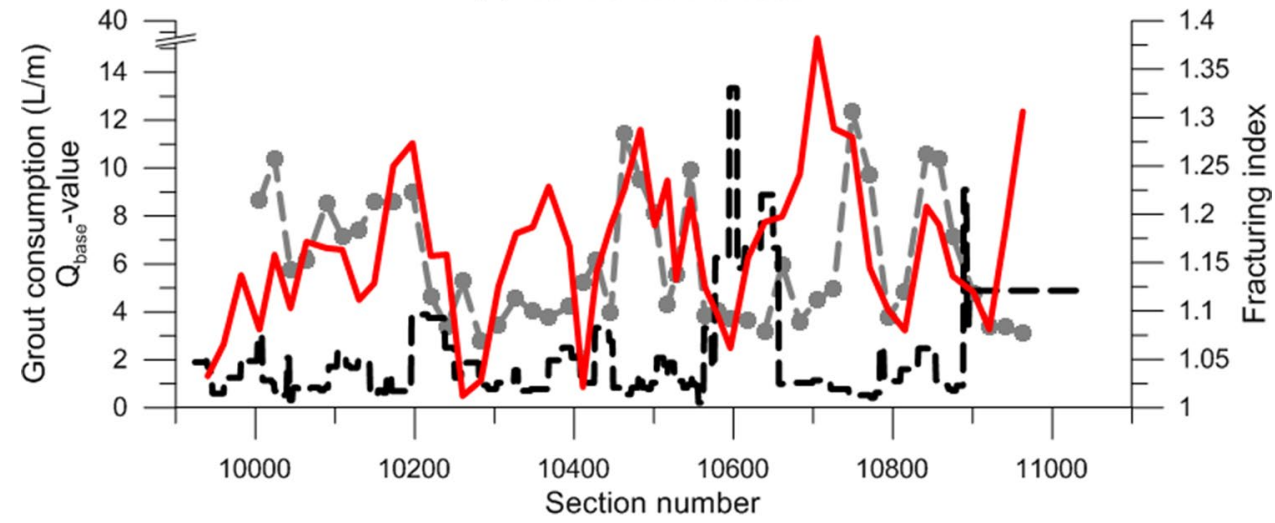

(b) Tunnel 201 North

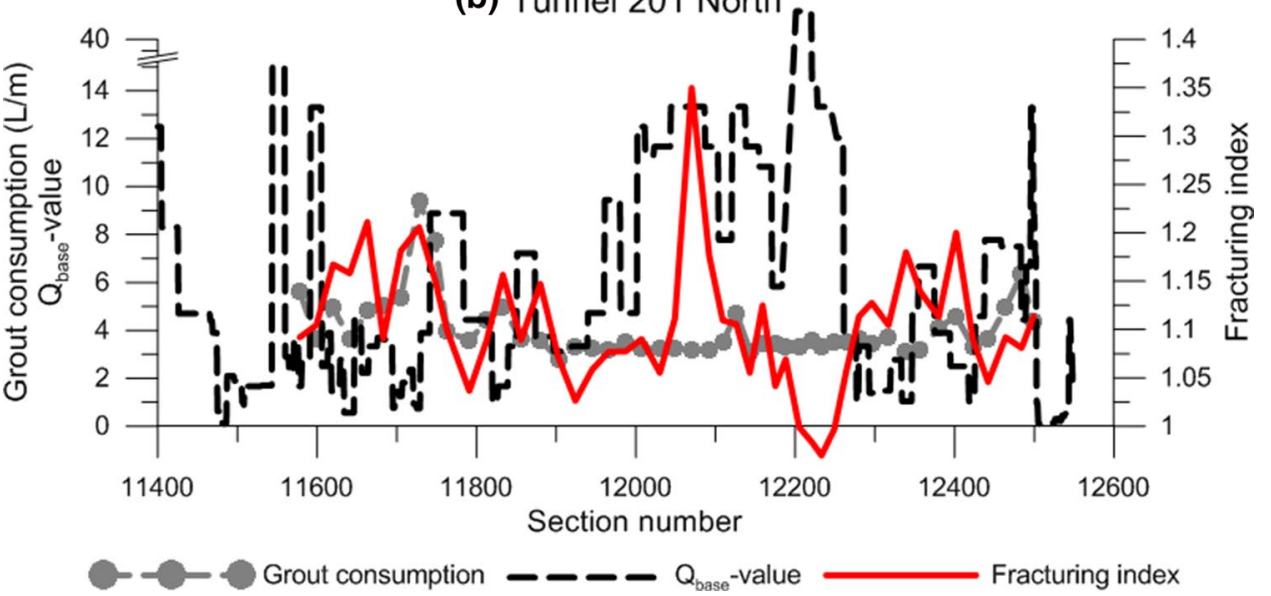

low $Q_{\text {base }}$ and high FI at seven umbrellas) and intrusive dikes (low grout consumption, medium to high $Q_{\text {base }}$ and high FI at six umbrellas). The categorization of the grout umbrellas is described in the sections below.

\subsection{Category A: No/Few Fractures}

In total 45 grout umbrellas with a relatively high $Q_{\text {base-value }}$ ( $Q_{\text {base }}>4$, rock class I or II) and low grout consumption $(<5.0 \mathrm{~L} / \mathrm{m}$; average $3.7 \mathrm{~L} / \mathrm{m})$ were assigned to category A. These sections had a relatively low number of joint sets and fractures. In addition, they showed a low mean fracturing index (0.97-1.19; average 1.08).

\subsection{Category B: Many Fractures}

In total 23 sections with a larger grout consumption $(\geq 4.8 \mathrm{~L} / \mathrm{m})$. During the geotechnical mapping, many fractures or small blocky rock masses were observed with a low $Q\left(Q_{\text {base }} \leq 4\right.$, rock class III or lower). The sections also had a high mean fracturing index (1.11-1.29; average 1.19). Therefore, they were classed as category B.

Fig. 7 Mean fracturing index and average grout consumption for each umbrella. It shows a correlation between these parameters, although it has a large spread. The red squares resemble outliers in the data 


\subsection{Category C: (Large) Fracture Zone}

Fifteen umbrellas fell into category $\mathrm{C}$, of which three had fractured intrusive dikes. In these sections, a larger amount of grout was consumed $(3.1-7.2 \mathrm{~L} / \mathrm{m}$; average $5.1 \mathrm{~L} / \mathrm{m})$, and fracture zones were observed during the geotechnical mapping. These fracture zones had a low $Q$ locally $\left(Q_{\text {base }} \leq 4\right.$, rock class III or lower), but were surrounded by favorable rock mass, as expected in category $\mathrm{C}$. These sections may show a high mean fracturing index locally, and this may partly be diluted in the rest of the MWD data of the grout umbrella (umbrella FI: 1.01-1.35; average 1.15).

\subsection{Category D: Few Large, Open Fractures}

One umbrella displayed only a few fractures and no fracture zones during the geotechnical mapping (high $Q_{\text {base }}>4$, rock class I or II). This umbrella would have been assigned to category A, based purely on the rock mass description and fracturing index (1.08), but the umbrella had a large grout consumption $(8.7 \mathrm{~L} / \mathrm{m})$. Although the cause was uncertain, this high grout volume was most likely caused by a few/ single, large, open fractures. The umbrella had a low mean fracturing index. The discrepancy could have resulted from a lack of precision in MWD recordings. Peng et al. (2005) determined single voids $<1.5 \mathrm{~mm}$ do not affect the MWD parameters in (percussive) drilling systems. Besides, in the present study, the MWD interval recording was set to $2 \mathrm{~cm}$ (practice 2-3 cm); intersecting of large single fractures $(<2 \mathrm{~cm})$ may go unnoticed because of this sampling interval, even though these individual fractures could consume a tremendous amount of grout. This favorable rock mass with high grout consumption was assigned to category D.

\subsection{Category E: Clay-Filled Fractures/Weathered Rock Mass}

Seven umbrellas fell in category E. These umbrellas displayed low grout consumption $(3.5-4.6 \mathrm{~L} / \mathrm{m}$; average 4.0 $\mathrm{L} / \mathrm{m})$ and low $Q$-values ( $Q_{\text {base }} \leq 4$, rock class III or lower) during the geotechnical mapping. Severely weathered rock mass and/or significant amounts of clay were also observed. With clay-filled fractures and/or a high degree of weathering, a rock mass will be of poor quality, and the clay content will hamper the spread of the injected grout. These umbrellas displayed a high mean fracturing index (1.13-1.24; average 1.19) caused by the alternation of clay and fractured rock mass. Solely based on the MWD and rock mass description, they would have been assigned to category B, but because of the effect of the clay on the grouting, they were assigned to category $\mathrm{E}$.

\subsection{Category F: Intrusive Dikes}

Six umbrellas showed the effect of competent intrusive dikes on drilling and grouting. These grout umbrellas displayed favorable rock mass conditions and low grout consumption (3.1-3.6 L/m; average $3.3 \mathrm{~L} / \mathrm{m}$ ), but a high fracturing index (1.18-1.35; average 1.24). In this case study, several granite, diabase and pegmatite dikes were observed. These umbrellas were assigned to category F. Depending on the rock type, the fracturing index can vary, even though the rock mass is solid and competent, e.g., a competent fine-grain granite has a low fracturing index, whereas a competent pegmatite may have a high fracturing index. This agrees with the findings of Van Eldert et al. (2016). These researchers observed that alternating phenocrysts could falsely portray the rock mass as fractured in the MWD data. If only the MWD data were taken into account, the umbrellas would be considered category $\mathrm{B}$ or category $\mathrm{C}$.

Figure 8 shows fracture index and grout consumption grouped for the different categories, the categories overlap and a strict separation between the classes could not be obtained. Unfractured rock masses (category A) show a low grout consumption $(<5.0 \mathrm{~L} / \mathrm{m})$ and fracturing index (generally $<1.14$ ), fractured rock masses (category $\mathrm{B}$ ) show a high grout consumption $(>4.8 \mathrm{~L} / \mathrm{m})$. Rock masses with fracture zones (category C) are displayed in-between category A and category B for both grout consumption $(3.1-7.2 \mathrm{~L} / \mathrm{m})$ and fracturing index (1.01-1.38). Anomalies (category D,

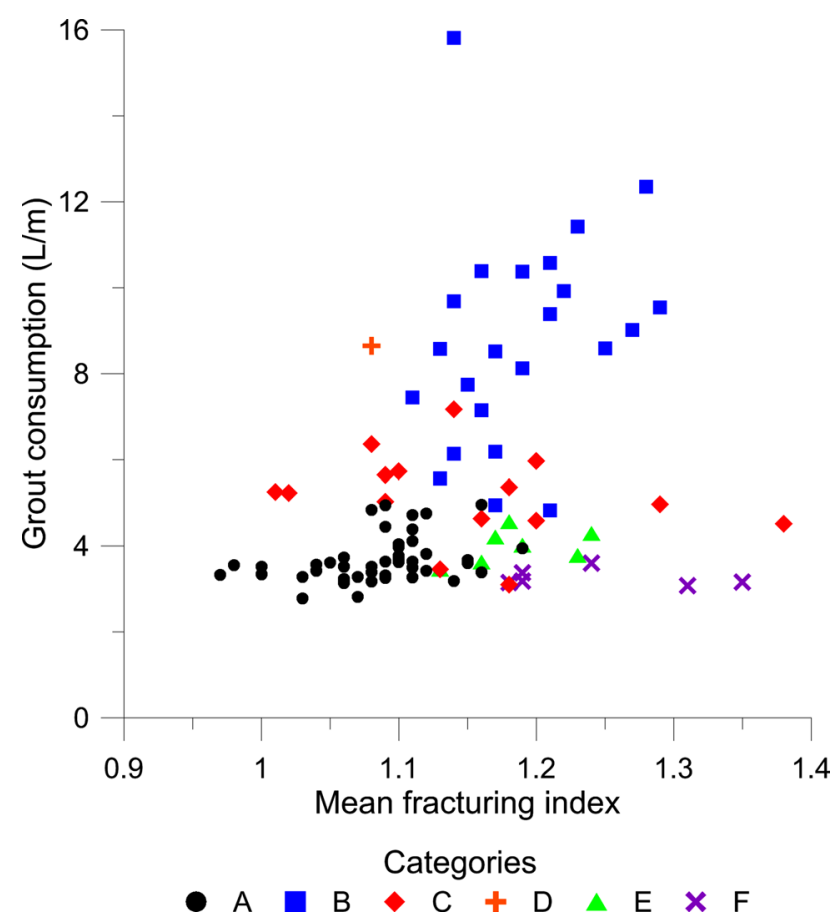

Fig. 8 Mean fracturing index and average grout consumption for each umbrella separate for each category 
category E and category F) show the expected values. The category D umbrella shows the low FI (1.08) but high grout consumption $(8.7 \mathrm{~L} / \mathrm{m})$. Category $\mathrm{E}$ and category $\mathrm{F}$ show a high fracture index (respectively, 1.13-1.24 and 1.18-1.35) but low grout consumption (respectively, 3.5-4.6 L/m and $3.1-3.6 \mathrm{~L} / \mathrm{m})$

\subsection{MWD Fracturing Index}

The fracturing index showed a reasonably strong correlation with the rock mass quality, with a high fracturing index indicating low quality and vice versa. Notable exceptions were the umbrellas with intrusive diabase and pegmatite (category F). Here, the fracturing index indicated worse rock mass conditions than was the case. In umbrellas 10,260, 10,283, and 10,411 , the fracturing index indicated a more favorable rock mass condition than was the case. The reason for the latter inaccurate portrayal of the rock mass by the fracturing index is unclear but could be explained by (changes in) drilling settings, alterations during the drilling or simply the subjectivity of rock mass classification (Van Eldert et al. 2020a).

In this study, in $70 \%$ of the tunnel, the fracturing index showed a good correlation with the grout consumption in both the un-fractured (category A, 46\%) and fractured (category B, 24\%) rock masses. Because of the occurrence of locally fractured zones (category C), an additional 15\% of the rock mass conditions and grout consumption could be predicted accurately with MWD. In total, the grout consumption was predicted by the MWD fracturing index in $85 \%$ of the umbrellas, categories A, B, and C. However, the fracturing index was unable to detect single large fractures (category $\mathrm{D}, 1 \%$ ). Both high clay content in fracture zones (category E, 7\% of the tunnel) and intrusive dikes (category $\mathrm{F}, 6 \%$ of the tunnel) displayed an increased fracturing index because of variations in drillability, but not an increase in grout consumption due to limited grout spread. Albeit, the MWD fracturing index was able to predict the rock mass quality in $93 \%$ of the umbrellas, namely categories A, B, $\mathrm{C}$, and $\mathrm{E}$. Improved rock mass assessment with the MWD fracturing index requires the collection of additional information during excavation. These can include the application of an accurate MWD water index to indicated drill fluid losses/inflows, as performed by Schunnesson et al. (2011), using the well-established water loss test for rock masses in categories B, C, E and F. In these cases, large drill fluid losses/inflows indicate, respectively, dry and water-bearing structures and thus the requirement for increased grouting. Besides, drilling observations or analysis for example the color of the flushing water could be used to determine rock mass conditions. At the southern part of the Stockholm bypass, white flushing fluid from the drill hole indicated high clay content in the rock mass (category E), where black flushing fluid indicated the occurrence of graphite zones in the rock mass. This additional data should be incorporated with rock quality assessment.

\subsection{Conceptual Method for Grout Decisions}

In tunnel excavations, where the set water ingress limits have a significant margin with the expected water ingress (low risk), the MWD FI could be used to determine the grout requirements. In these cases, pre-grouting requirements could be established based on a combination of the MWD fracturing index and additional water loss/gain measurements. Here, the opportunity exists to reduce the total number of grout umbrellas, which leads to reduced excavation time, cost, and environmental impact. Based on the previously presented results, the FI was incorporated in a conceptual method for grout decision in hydrologically low-risk areas, see Fig. 9. The conceptual method could be used to establish rock mass grouting categories A, E and $\mathrm{F}$; under the right circumstances (low risk) the tunnel sections in these categories do not require grouting. The suggested, conceptual method is initiated with probe (or grout) hole drilling. Based on the collected MWD data, the fracturing index is calculated. A low fracturing index indicates no grouting is required (category A), except for drill holes with large drill fluid losses or water inflow (category D). If the fracturing index is relatively high, a water loss test should be performed, e.g., a water pressure test (WPT, ISO 2012). This test will either show significant water losses (or gains) or not. In the case of extensive water loss (or gain), pre-grouting of the fractured rock mass (category B) or fracture zone (category C) is required to meet the set water ingress limits. When the water loss test reveals insignificant flow, pre-grouting may not be required. In this case, the relatively high fracturing index is most likely caused by fractured rock masses with clay filling (noticeable drill fluid color change, category E) or solid magmatic intrusions, e.g., pegmatite or diabase dikes (category F), and, therefore, already sealed. In this study

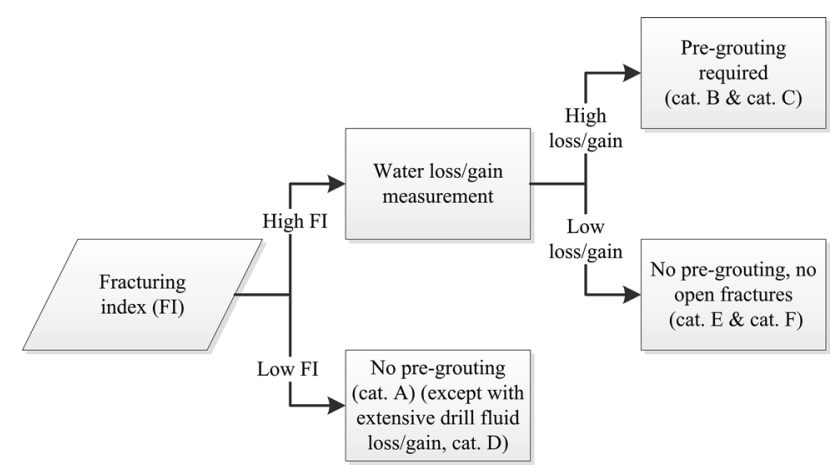

Fig. 9 Conceptual method for pre-grouting requirements based on fracturing index and water loss tests 
up to $59 \%$ of the grout umbrellas may not have required (extensive) grouting, namely categories A (46\%), E (7\%), and $\mathrm{F}(6 \%)$.

\section{Concluding Remarks}

The study showed grout consumption was correlated to a rock mass's degree of fracturing, as observed in both the geotechnical mapping $\left(Q_{\text {base }}\right)$ and the MWD fracturing index. A similar correlation appeared for grouting, except severely weathered and clay-rich areas (reduced grout spread) single, large, open fractures, and intrusions and cemented veins. These rock mass conditions cannot be determined purely based on MWD. Large fractures, though less than $2 \mathrm{~cm}$ with cannot be observed in the current MWD recordings. Nor can MWD data distinguish between fractured rock mass and the occurrence of cemented veins or intrusive dikes within the solid rock mass. In these cases the drilling behavior is very similar to the drilling of fractured rock masses; the MWD parameters show large variations in the recorded values.

Based on the overall findings, the study proposed a conceptual method to reduce the number of pre-grout umbrellas by incorporating the MWD fracturing index and water loss tests. In all, the following conclusions of the study could be drawn:

- The MWD fracturing index predicted rock mass quality for $93 \%$ of the tunnel, with categories A, B, C, and E.

- The MWD fracturing index predicted grout consumption for $85 \%$ of the tunnel, with categories A, B, and C.

- The grout consumption prediction could be improved with accurate water loss measurements and the use of indicators for clay content.

- The conceptual model, based on the MWD fracturing index and additional information, could potentially eliminate $59 \%$ of the grout umbrellas found in this study, namely categories $\mathrm{A}, \mathrm{E}$, and $\mathrm{F}$.

Although the study shows MWD technology provides a good indication of the rock mass conditions and grouting requirements, the derived indices should not be seen as a replacement for current data, e.g., geotechnical mapping and grout classification before the excavation. The MWD data is an additional information source, collected during excavation and can supplement the current rock mass quality designation and grout design decisions methods. The FI should be incorporated in the common practice of the observational method. In addition, the conceptual model is designed for low-risk situations and the model should be applied conservatively.
Acknowledgements The authors wish to thank Subterra Sweden and Trafikverket (Swedish Traffic Administration) for the MWD and grouting data, and Swedish Transport Administration (Trafikverket) and AFRY (formerly $\AA$ F) for the geotechnical mapping data of the tunnel. In addition, the authors acknowledge BeFo (Stiftelsen Bergteknisk Forskning, Rock Engineering Research Foundation) and Swebrec (Swedish Blasting Research Centre) for providing the initial funding for this study within BeFo project 344.

Funding Open access funding provided by Lulea University of Technology. Initial funding for the project was supplied within BeFo project 344.

\section{Compliance with Ethical Standards}

Conflict of interest The authors declare that they have no conflict of interest.

Open Access This article is licensed under a Creative Commons Attribution 4.0 International License, which permits use, sharing, adaptation, distribution and reproduction in any medium or format, as long as you give appropriate credit to the original author(s) and the source, provide a link to the Creative Commons licence, and indicate if changes were made. The images or other third party material in this article are included in the article's Creative Commons licence, unless indicated otherwise in a credit line to the material. If material is not included in the article's Creative Commons licence and your intended use is not permitted by statutory regulation or exceeds the permitted use, you will need to obtain permission directly from the copyright holder. To view a copy of this licence, visit http://creativecommons.org/licenses/by/4.0/.

\section{References}

ÅF (2016-2019) Project E4 Förbifart Stockholm, Kartering och förstärkningsanvisning. Unpublished data

Arghe F (2016) E4 Förbifart Stockholm FSE209 Bergtunnlar Skärholmen-Ingenjörsgeologisk prognos-Bergteknik Handling 13.5-Bygghandling 2015-03-04 (Rev B 2016-03-17) 2B141102-FSE209 [E4 Stockholm bypass FSE209 rock tunnelsSkärholmen-Engineering geological prognose-rock technical document 13.5-Construction document .... . Technical report (in Swedish)

Barton N, Lien R, Lunde J (1974) Engineering classification of rock masses for design of tunnel support. Rock Mech 6(4):189-236

Bhasin R (2002) Frøyatunnelen Vurdering av injeksjon i forhold til Q-parametre [Frøya tunnel assessment of grouting in relation to Q-parameters]. Statens vegvesen Rapport nr. 11, Intern report nr 2261, rapport nr. 20001042 (in Norwegian)

Brown ET, Barr MV (1978) Instrumented drilling as an aid to site investigations. In: Proceedings of 3rd international congress, International Association for Engineering Geology, vol 1, Madrid, Spain, pp 21-28

Doe TW, Geier JE (1990) Interpretation of fracture system geometry using well test data. SKB technical report Stripa project 91-03

Ghosh R, Danielsson M, Gustafson A, Falksund H, Schunnesson $\mathrm{H}$ (2017) Assessment of rock mass quality using drill monitoring technique of hydraulic ITH drills. Int J Min Miner Eng 8(3):169-186

Gustafson G, Stille H (1996) Prediction of groutability from grout properties and hydrogeological data. Tunnel Undergr Space Technol 11(3):325-332 
Gustafson G, Stille H (2005) Stop criteria for cement grouting. Felsbau 23(3):62-68

Haukaas K (2010) Bever Team 3 Operators' Manual, 103-118

Hernqvist L, Butrón C, Fransson Å, Gustafson G, Funehag J (2012) A hard rock tunnel case study: characterization of water-bearing fracture system for tunnel grouting. Tunnel Undergr Space Technol 30:132-144. https://doi.org/10.1016/j.tust.2012.02.014

Høien AH, Nilsen B (2014) Rock mass grouting in the Løren tunnel: case study with the main focus on the groutability and feasibility of drill parameter interpretation. Rock Mech Rock Eng 47:947-983

International Organization for Standardization [ISO] (2012) 222823:2012 Geotechnical investigation and testing — geohydraulic testing-part 3: water pressure tests in rock

International Organization for Standardization [ISO] (2016) 2247615:2016 geotechnical investigation and testing-field testingpart 15: measuring while drilling

Kvartsberg S (2013) On the use of engineering geological information in rock grouting design. Licentiate Dissertation, Department of Civil and Environmental Engineering, Chalmers University of Technology, Gothenburg, Sweden

Martinsson L, Bengtsson F (2010) Tillämpning av MWD vid utformning av injektering. [Application of MWD with configuring of grouting]. BKs 55:e årsmöte 2010, 9 March 2010, Bergsprängningskommittén, Stockholm, Sweden (in Swedish)

Navarro J, Segarra P, Sanchidrián JA, Castedo R, Perez Fortes AP, López LM (2018) Application of an in-house MWD system for quarry blasting. In: Proceedings of the 12th international symposium on rock fragmentation by blasting, Fragblast 12, Luleå, Sweden, pp 203-207

Palmström A, Broch E (2006) Use and misuse of rock mass classification systems with particular reference to the Q-system. Tunnel Undergr Space Technol 21(6):575-593

Peng S, Tang D, Sasaoka T, Luo Y, Finfinger G, Wilson G (2005) A method for quantitive void/fracture detection and estimation of rock strength for underground mine roof. In: 24th international conference on ground control in mining, Morgantown, West Virginia, United States of America, pp 187-195

Rødseth M (2013) Analyse av sammenhenger mellom MWD-data og bergmekaniske parameter [Analysis of correlations between MWD data and rock mechanical parameters]. Master's thesis, Norges teknisk-naturvitenskapelige universitet, Trondheim, Norway (in Norwegian)

Schunnesson H (1996) RQD predictions based on drill performance parameters. Tunnel Undergr Space Technol 11(3):345-351

Schunnesson H (1998) Rock characterisation using percussive drilling. Int J Rock Mech Min Sci 35(6):711-725

Schunnesson H, Elsrud R, Rai P (2011) Drill monitoring for ground characterization in tunnelling operations. In: Proceedings of 20th international symposium on mine planning and equipment selection (MPES2011), 12-14 October 2011, National Center on Complex Procession of Mineral Raw Materials of the Republic of Kazakhstan, Almaty, Kazakhstan

Trafikverket (2015a) E4 Förbifart Stockholm Sätra gemensamtFSE209 ingenjörsgeologisk prognos huvudtunnlar km 9/93510/978. Ritningsnummer: 200B1211

Trafikverket (2015b) E4 Förbifart Stockholm Sätra gemensamtFSE209 ingenjörsgeologisk prognos huvudtunnlar km 10/97811/946. Ritningsnummer: 200B1212

Trafikverket (2015c) E4 Förbifart Stockholm Sätra gemensamtFSE209 ingenjörsgeologisk prognos huvudtunnlar km 11/94612/975. Ritningsnummer: 200B1213

Trafikverket (2017) Komplettering av injekteringshål, Tunnel 201 Section 12108, 2017-07-07

Trafikverket (2018) Var med och bygg E4 Förbifart Stockholm Sveriges största väg-och tunnelprojekt, E4 Förbifart Stockholm, https ://www.trafikverket.se/contentassets/5fd4779c3bfa4adbac7ba1c29 6598f12/upphandling_fs_webb.pdf. Accessed 11 Dec 2019

Van Eldert J, Ittner H, Schunnesson H, Johansson D (2016) Evaluation of valuation of alternative techniques for excavation damage characterization. In: ITA-AITES World Tunnel Congress 2016 (WTC 2016), 22-28 April 2016, San Francisco, California, United States of America

Van Eldert J, Funehag J, Saiang D, Schunnesson H (2020) Rock support prediction based on measurement while drilling technology. Bull Eng Geol Environ. https://doi.org/10.1007/s10064-02001957-x

Van Eldert J, Schunnesson H, Johansson D, Saiang D (2020) Application of measurement while drilling technology to predict rock mass quality and rock support for tunnelling. Rock Mech Rock Eng 53:1349-1358. https://doi.org/10.1007/s00603-019-01979-2

Van Eldert J, Schunnesson H, Saiang D, Funehag J (2020) Improved filtering and normalizing of Measurement While Drilling data in tunnel excavation. Tunnel Undergr Space Technol 2020:V103. https://doi.org/10.1016/j.tust.2020.103467

Widmann R (1996) International society for rock mechanics commission on rock grouting. Int J Rock Mech Min Sci Geom Abstr V 33(8):803-847

Zetterlund M, Martinsson L, Dalmalm T (2017) Implementation of MWD - data for grouting purposes in a large infrastructure project-the Stockholm bypass. In: Proceedings of grouting 2017, 9-12 July 2017, Honolulu, Oahu, Hawaii, United State of America, 61-70

Publisher's Note Springer Nature remains neutral with regard to jurisdictional claims in published maps and institutional affiliations. 